\title{
TECHNIQUES OF ADJUSTING OPACITY ESTIMATES OF THE DIESEL EXHAUST GASES
}

\author{
Igor Blyankinshtein, Evgeniy Voevodin, Anatoliy Ruban
}

Siberian Federal University, prospekt Svobodny, 79, Krasnoyarsk, 660041, Russian Federation

\begin{abstract}
The Rules of UNECE № 24 regulated a test method of diesels on the mode of free acceleration. Thus one of procedures provides obtaining opacity estimates of the exhaust gases in very subjective method. Due to the fact that this procedure doesn't include quantitative parameters, it can be understood and implemented by operators differently, that consequently leads to considerable dispersion in results of opacity measurements in practice.

Mathematical models of opacity of the exhaust gases depending on rate of movement of a fuel feed pedal is obtained. The technique of a correcting of opacity estimates of the exhaust gases of diesels on the mode of free acceleration with use of static and dynamic models is offered.
\end{abstract}

Keywords exhaust gases of diesels; opacity estimates; techniques of correcting; static and dynamic models; tests of diesel
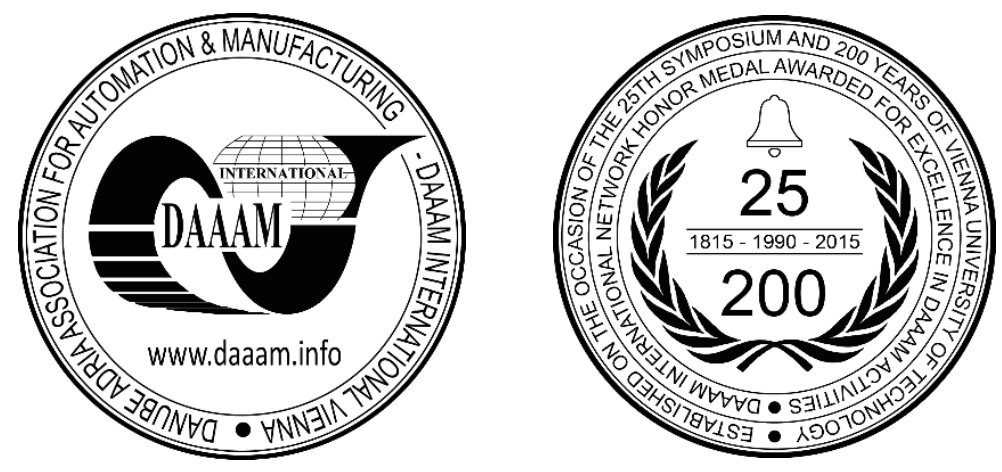

This Publication has to be referred as: Blyankinshtein, I[gor]; Voevodin, E[vgeniy] \& Ruban, A[natoliy] (2016). Techniques of Adjusting Opacity Estimates of the Diesel Exhaust Gases, Proceedings of the 26th DAAAM International Symposium, pp.0883-0891, B. Katalinic (Ed.), Published by DAAAM International, ISBN 978-3-902734-07-5, ISSN 1726-9679, Vienna, Austria

DOI: $10.2507 / 26$ th.daaam.proceedings. 123 


\section{Introduction}

In the coming decades, diesel will remain an important power plant of vehicles, therefore researchers give significant consideration to improvement of its working process, structure, transfer to alternative fuels and hazardous emission reduction [1-8]. However, when assessing the opacity of exhaust gases of diesel engines there is a problem caused by the testing imperfection. So the appendix of 5 Rules of UNECE No. 24 has regulated a test method of diesels on the mode of free acceleration. Thus one of procedures provides obtaining opacity estimates of the exhaust gases in very subjective method, namely «... due to rapid, but not sudden pressing a fuel feed pedal the maximum capacity rate of fuel pump is achieved which is supported before obtaining by the engine of the maximum number of turns and regulator turn-on» (article 2.5 of the Appendix of 5 Rules of UNECE No. 24) [9]. Due to the fact that this procedure doesn't include quantitative parameters, it can be understood and implemented by operators differently, that consequently leads to considerable dispersion in results of opacity measurements in practice.

Research of this issue has shown that rate (time, duration, s) movements of a fuel feed pedal while measuring opacity of the exhaust gases of diesels with the mechanical drive of the fuel pump has significant impact on results of measurement in free acceleration mode [10].

This problem is partially solved with the help of a statistical method prescribed in article 2.6 of the Appendix of 5 Rules of UNECE No. 24 - conducting 6 measurements and averaging of the last of four of them. However, it does not guarantee constant results. The second solution known is based on the use of automatic drives realizing the set rate of control element movement. However, due to its use testing is complicated considerably and becomes more expensive [11, $12]$.

\section{The proposed method}

The authors propose an alternative method based on use of mathematical models of opacity of the exhaust gases in free acceleration mode in a function from a movement rate of fuel feed pedal [13, 14].

Static models of peak opacity constructed on the basis of the regression equations have the following form:

$$
D=D_{0}+a \cdot e^{-b t}
$$

where $D_{0}$ - a measured value of opacity in a set mode at a maximum crank shaft speed, $\% ; t$ - time (duration) of free acceleration mode, s; $a$ and $b$ - equation coefficients; $a \cdot e^{(-b t)}-$ a component of opacity taking into account free acceleration mode.

As compared to other possible variants, the structure of model (1) corresponds to the nature of transient period under consideration better: in case of long duration of the transient process, the second summand approaches zero, and evaluation of opacity approaches its value in the set mode at a maximum shaft speed $D_{0}$ (fig. 1).

In order to determine parameters of the additive model offered, it is necessary to have at least two points of an exponential curve, that is, two pairs of measurements $D_{1}, t_{1}, D_{2}, t_{2}$ and $D_{0}$. You can draw a system with a corresponding number of equations for these two points:

$$
\left\{\begin{array}{l}
D_{1}=D_{0}+\mathrm{a} \cdot \exp ^{-\mathrm{b} \cdot \mathrm{t} 1} \\
D_{2}=D_{0}+\mathrm{a} \cdot \exp ^{\mathrm{b} \cdot \mathrm{t} 2}
\end{array}\right.
$$

where D1, D2 - exhaust gases opacity in free acceleration mode, $\%$; $1, \mathrm{t} 2$ - time of change of the procedural parameter when implementing free acceleration mode, s.

By solving this system, we will find required parameters of the model:

$$
\left\{\begin{array}{l}
a=\left(D_{1}-D_{0}\right) /\left(-e^{\left(-b \cdot t_{1}\right)}\right) \\
b=\ln \left[\left(D_{1}-D_{0}\right) /\left(D_{2}-D_{0}\right)\right] /\left(t_{2}-t_{1}\right)
\end{array}\right.
$$

Thus, we can recommend the following model for further use:

$$
D=D_{0}+\left(D_{i}-D_{0}\right) / e^{-b \cdot(t} \varphi i^{-t)}
$$

where $b=\ln \left[\left(D_{1}-D_{0}\right) /\left(D_{2}-D_{0}\right)\right] /\left(t_{2}-t_{1}\right) ; D-$ an adjusted value of opacity indicator, \%; $D_{i}-$ value of opacity indicator during the $i$-th measurement, $\% ; t_{\varphi i}$ - value of time necessary to change a parameter characterizing rate of fuel feed pedal pressing, $\mathrm{s} ; t_{\mathrm{r}}-\mathrm{a}$ regulated value of time characterizing the rate of fuel feed pedal pressing; $D_{0}$ - measured value of opacity in a set mode at a maximum crank shaft speed, $\%$. 


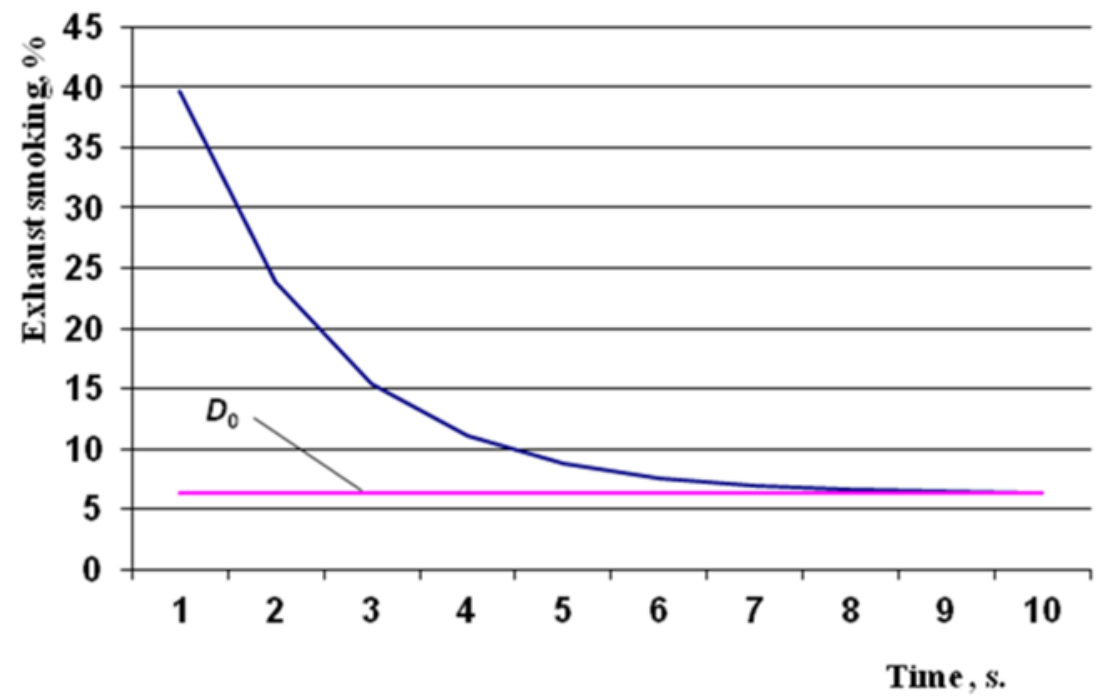

Fig. 1. The graph of behavior of peak exhaust opacity in free acceleration mode as a function of the time of the transition process

In order to identify parameters of the static models, an experimental evaluation of exhaust gases opacity dependence in free acceleration mode on the parameters characterizing rate of fuel feed pedal pressing.

In accordance with the experiment plan the following procedural parameters registered by equipment were taken as an independent variable: $t_{\varphi}$ - time of fuel feed pedal movement from $\varphi_{\min }$ to $\varphi_{\max } ; t_{n}$ - time of change of crank shaft speed from $\mathrm{n}_{\mathrm{xx} \min }$ to $\mathrm{n}_{\mathrm{xx} \max } ; t_{\mathrm{v}}$ - time of increase of exhaust flow rate from $\mathrm{V}_{\mathrm{eg}}$ at $\mathrm{n}_{\mathrm{xx} \text { min }}$ to $\mathrm{V}_{\mathrm{eg}}$ at $\mathrm{n}_{\mathrm{xx} \max }$.

The experimental data was processed using typical software for statistical processing.

The parameters of static models of exhaust gases opacity in free acceleration mode obtained as a result of processing for KamAZ-5410, equipped with engine of model 740.01, are shown in Table 1.

\begin{tabular}{|c|c|c|c|}
\hline \multirow{2}{*}{$\begin{array}{l}\text { Type of an equation: } \\
D(t)=D_{0}+a \cdot \exp ^{b \cdot t}\end{array}$} & \multicolumn{3}{|c|}{ Procedural parameter } \\
\hline & $t_{\varphi}$ & $t_{\mathrm{n}}$ & $t_{\mathrm{v}}$ \\
\hline Parameters of an equation & $\begin{array}{c}a=47.61804, \\
b=-0.6034765\end{array}$ & $\begin{array}{c}a=72.42525, \\
b=-0.6615941\end{array}$ & $\begin{array}{l}a=63.97547, \\
b=-0.649241\end{array}$ \\
\hline Correlation coefficient $R$ & -0.9681571 & -0.9736726 & -0.966405 \\
\hline Determination coefficient $R^{2}$ & 0.9373281 & 0.9480384 & 0.9339387 \\
\hline t-statistics of correlation coefficient & 15.48161 & 17.10212 & 15.05132 \\
\hline Level of coefficient $R$ significance & 0.99 & 0.99 & 0.99 \\
\hline Average approximation error, $\%$ & 27.59605 & 23.32192 & 27.51646 \\
\hline$S$ - residual dispersion & 6.877402 & 7.899442 & 9.37534 \\
\hline Dispersion Fisher's ratio & 6.835931 & 5.181478 & 3.678515 \\
\hline Level of adequacy & 0.99 & 0.99 & 0.99 \\
\hline
\end{tabular}

Table 1. The parameters of static models obtained as a result of experimental data processing for KamAZ

Graphical representation of the models is shown in fig. $2 a-c$.

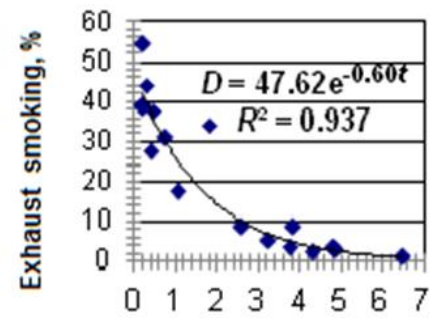

a

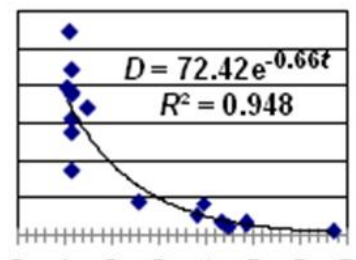

$\begin{array}{llllllll}0 & 1 & 2 & 3 & 4 & 5 & 6 & 7\end{array}$

b

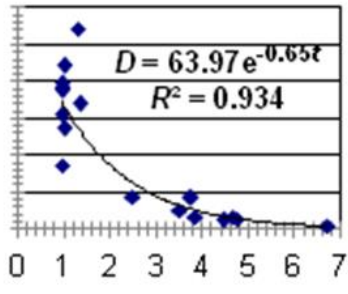

c

Fig. 2. The behavior of peak exhaust gases opacity according to parameters: $a$-according to time of fuel feed pedal movement from $\varphi_{\min }$ to $\varphi_{\max } ; b$ - according to time of change of crank shaft speed from $\mathrm{n}_{\mathrm{xx} \min }$ to $\mathrm{n}_{\mathrm{xx} \max } ; \mathrm{c}-\operatorname{according}$ to time of increase of exhaust flow rate from $V_{\text {eg }}$ at $n_{x x \min }$ to $V_{e g}$ at $n_{x x \max }$. 
According to the results of conducted analysis, we have made a conclusion about possibility of use (for acceleration time more than 1 second) of any of the following parameters as a signal containing information about input control: time of fuel feed pedal movement (fig. 2a), time of change of crank shaft speed from minimum to maximum idle running rate (fig. 2b), and time of increase of exhaust flow rate (fig. 2c). The last two parameters are not informative in case of fuel feed pedal pressing for less than 1 second.

Dynamic models, reflecting a character of opacity formation (change) in time in free acceleration mode are based on differential and difference equations using a method of sequential linearization, developed and generalized for extremal problems $[15,16]$. The point is that there is an object (system) (see fig. 3) dynamic characteristics of which shall be identified. A disturbing signal $u(t)$ is sent to object input, and its reaction $y^{*}(t)$ is removed at object output.

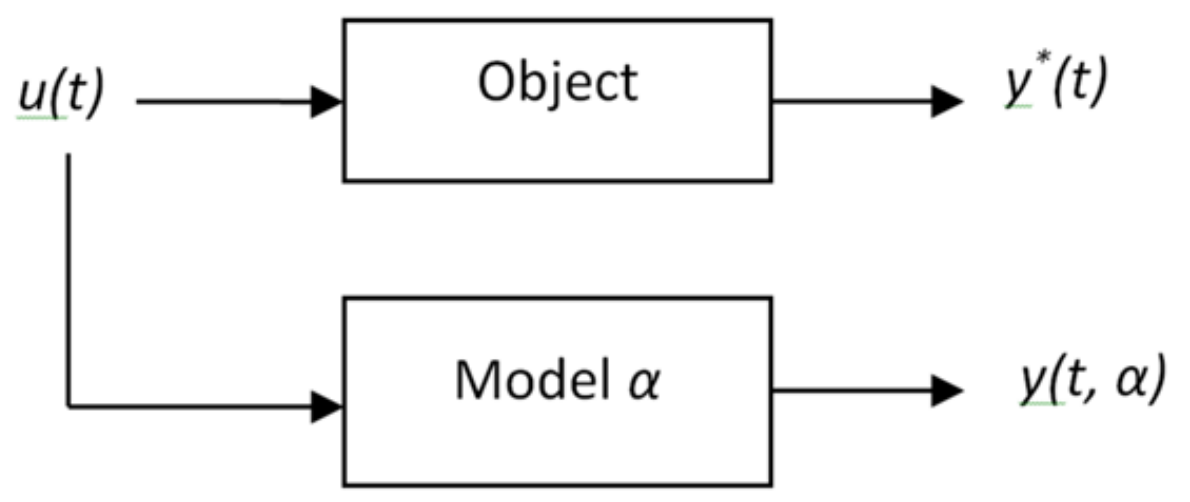

Fig. 3. Graphical representation of an identification object

An input and output signals are registered by measuring equipment and saved on a medium. It is necessary to build a model adequately connecting the input and the output. Where $u(t)$ - a disturbing factor, time dependant (in our case fuel feed pedal movement); $y^{*}(t)$ - actual output (outcome of the experiment - exhaust gases opacity); $y(t, \alpha)$ - output of the model; $t \in[0 ; T]$; $\alpha-\mathrm{a}$ vector of model parameters.

At the first stage any equation can be used as a model: ordinary differential equation, ordinary difference equation and so on, to the accuracy of parameter $\boldsymbol{\alpha}$.

Based on measurements of object input and output $\left(u\left(t_{i}\right), y^{*}\left(t_{i}\right), i=\overline{1, n}\right)$, it is necessary to find parameters of model $\boldsymbol{\alpha}$. Let us analyze identification of dynamic characteristics using method of sequential linearization on the example of a differential first-order equation

$$
\frac{\mathrm{d} y(t)}{\mathrm{d} t}=\alpha_{1} \cdot y(t)+\alpha_{2} \cdot u(t), y(0)=\alpha_{0}
$$

Solution of this equation depends on parameters $\alpha=\left(\alpha_{0}, \alpha_{1}, \alpha_{2}\right)$ and is found using Runge-Kutta's method. Parameters $\boldsymbol{\alpha}$ are calculated from least-squares criteria

$$
I(\alpha)=\sum_{i=1}^{n}\left(y^{*}\left(t_{i}\right)-y\left(t_{i}, \alpha\right)\right)^{2} \rightarrow \min _{\alpha}
$$

Let us denote by $\alpha^{l}$ parameters calculated at 1-th iteration and by $\alpha^{l+1}$ parameters calculated at $(l+1)$-th iteration, and build an iteration procedure of recursive revaluation of $\alpha^{l+1}$ according to $\alpha^{l}$.

Increment of parameters $\Delta \alpha^{l+1}=\left(\Delta \alpha_{0}^{l+1}, \Delta \alpha_{1}^{l+1}, \Delta \alpha_{2}^{l+1}\right)$ are calculated from a quadratic criterion (using linearized model output)

$$
\begin{gathered}
\bar{I}^{l+1}=\sum_{i=1}^{n}\left(y^{*}\left(t_{i}\right)-y^{l}\left(t_{i}, \alpha\right)-\frac{\mathrm{d} y^{l}\left(t_{i}, \alpha\right)}{\mathrm{d} \alpha_{0}} \cdot \Delta \alpha_{0}^{l+1}-\frac{\mathrm{d} y^{l}\left(t_{i}, \alpha\right)}{\mathrm{d} \alpha_{1}} \cdot \Delta \alpha_{1}^{l+1}-\right. \\
\left.-\frac{\mathrm{d} y^{l}\left(t_{i}, \alpha\right)}{\mathrm{d} \alpha_{2}} \cdot \Delta \alpha_{2}^{l+1}\right)^{2} \rightarrow \min _{\Delta \alpha^{l+1}}
\end{gathered}
$$

Derivatives $\frac{\mathrm{d} y^{l}(t, \alpha)}{\mathrm{d} \alpha_{0}}=\omega_{\alpha_{0}}^{l}(t), \frac{\mathrm{d} y^{l}(t, \alpha)}{\mathrm{d} \alpha_{1}}=\omega_{\alpha_{1}}^{l}(t), \frac{\mathrm{d} y^{l}(t, \alpha)}{\mathrm{d} \alpha_{1}}=\omega_{\alpha_{2}}^{l}(t)$ are called sensitivity functions.

Sensitivity functions are calculated using sensitivity equations: 


$$
\left\{\begin{array}{l}
\frac{\mathrm{d} \omega^{l} \alpha_{0}(t)}{\mathrm{d} t}=\alpha_{1} \cdot \omega^{l} \alpha_{0}(t) \\
\frac{\mathrm{d} \omega^{l} \alpha_{1}(t)}{\mathrm{d} t}=\alpha_{1} \cdot \omega^{l} \alpha_{1}(t)+y^{l}(t), \quad \omega_{\alpha_{0}}^{l}(0)=1 ; \\
\frac{\mathrm{d} \omega^{l} \alpha_{2}(t)}{\mathrm{d} t}=\alpha_{1} \cdot \omega_{\alpha_{2}}^{l}(t)+u(t), \quad \omega_{\alpha_{2}}^{l}(0)=0
\end{array}\right.
$$

In order to solve sensitivity equations we also use numerical quadrature methods.

A necessary condition of functional $I^{l+1}$ (3) minimum results in solution of a system of linear heterogeneous algebraic equations:

$$
\left\{\begin{array}{l}
\sum_{i=1}^{n}\left(\omega_{\alpha_{0}}^{l}\left(t_{i}\right)\right)^{2} \Delta \alpha_{0}^{l+1}+\sum_{i=1}^{n} \omega_{\alpha_{0}}^{l}\left(t_{i}\right) \omega_{\alpha_{1}}^{l}\left(t_{i}\right) \Delta \alpha_{1}^{l+1}+\sum_{i=1}^{n} \omega_{\alpha_{0}}^{l}\left(t_{i}\right) \omega_{\alpha_{2}}^{l}\left(t_{i}\right) \Delta \alpha_{2}^{l+1}=\sum_{i=1}^{n} \omega_{\alpha_{0}}^{l}\left(t_{i}\right)\left(y^{*}\left(t_{i}\right)-y^{l}\left(t_{i}, \alpha\right)\right) ; \\
\sum_{i=1}^{n} \omega_{\alpha_{1}}^{l}\left(t_{i}\right) \omega_{\alpha_{0}}^{l}\left(t_{i}\right) \Delta \alpha_{0}^{l+1}+\sum_{i=1}^{n}\left(\omega_{\alpha_{1}}^{l}\left(t_{i}\right)\right)^{2} \Delta \alpha_{1}^{l+1}+\sum_{i=1}^{n} \omega_{\alpha_{1}}^{l}\left(t_{i}\right) \cdot \omega_{\alpha_{2}}^{l}\left(t_{i}\right) \Delta \alpha_{2}^{l+1}=\sum_{i=1}^{n} \omega_{\alpha_{1}}^{l}\left(t_{i}\right)\left(y^{*}\left(t_{i}\right)-y^{l}\left(t_{i}, \alpha\right)\right) ; \\
\sum_{i=1}^{n} \omega_{\alpha_{2}}^{l}\left(t_{i}\right) \omega_{\alpha_{0}}^{l}\left(t_{i}\right) \Delta \alpha_{0}^{l+1}+\sum_{i=1}^{n} \omega_{\alpha_{2}}^{l}\left(t_{i}\right) \omega_{\alpha_{1}}^{l}\left(t_{i}\right) \Delta \alpha_{1}^{l+1}+\sum_{i=1}^{n}\left(\omega_{\alpha_{2}}^{l}\left(t_{i}\right)\right)^{2} \Delta \alpha_{2}^{l+1}=\sum_{i=1}^{n} \omega_{\alpha_{2}}^{l}\left(t_{i}\right)\left(y^{*}\left(t_{i}\right)-y^{l}\left(t_{i}, \alpha\right)\right) .
\end{array}\right.
$$

By solving this system, we define corrections $\Delta \alpha^{l+1}{ }_{0}, \Delta \alpha^{l+1}{ }_{1}, \Delta \alpha^{l+1}{ }_{2}$ to coefficient at the stage $(l+1)$. Parameters at the next iteration $\alpha^{l+1}$ are expressed using parameters of the previous iteration $\alpha^{l}$ and increment $\Delta \alpha^{l+1}$ by the formula

$$
\alpha^{l+1}=\alpha^{l}+\gamma^{l} \cdot \Delta \alpha^{l+1} .
$$

Positive coefficient $\gamma^{l}$ here is calculated under the condition of monotone convergence in functional $I$ (6)

$$
I^{l+1} \leq I^{l}
$$

where $I^{l}=I\left(\alpha^{l}\right)$.

An example of choice of $\gamma^{l}$ coefficient is sequence $(1 ; 1 / 2 ; 1 / 4 ; 1 / 8 ; \ldots)$.

Incremental iterations (approximations) shall be performed until condition $\left\|\Delta \alpha^{l+1}\right\| \leq \varepsilon_{1}$ or $\left|I^{l+1}-\boldsymbol{I}^{l}\right| \leq \varepsilon_{2}$ is met.

Since the equipment registered the parameters discretely in equal time intervals, it was easier, in calculation terms (because there was no need to integrate differential equations), to use discrete models - difference equations.

A dynamic model with the least complex structure was selected. We used in turns difference (corresponding to differential) equations of the third, fourth, fifth and sixth order. The results of the analysis showed that increase of equation order that is higher than the fourth one did not bring any considerable improvements to model quality - the functional (11) did not reduce, yet, a number of iterations grew greatly, which made an identification procedure more labor-intensive.

We also performed model regularization - when using a full differential fourth-order equation we dealt with a redundant equation, which caused deterioration of functional convergence to a minimum and, as a result, considerable increase of a number of iterations. That is why in order to characterize the input we used difference second-order components, and to characterize the output - fourth-order components. Such structure secures approaching a functional minimum using minimum number of iterations.

The best results were shown by a model with two inputs (the first input - position of the accelerator pedal $\boldsymbol{u}(\boldsymbol{t})$, and the second input - crank shaft speed $\boldsymbol{u}_{\boldsymbol{I}}(\mathrm{t})$ of the second order and output of the fourth order (exhaust gases opacity) $y(t)$ :

$$
\begin{aligned}
& y[t]=\alpha_{1} \cdot y[t-1]+\alpha_{2} \cdot y[t-2]+\alpha_{3} \cdot y[t-3]+\alpha_{4} \cdot y[t-4]+\alpha_{5} \cdot u[t-1]+\alpha_{6} \cdot u[t-2]+\alpha_{7} \cdot u_{1}[t-1]+\alpha_{8} \cdot u_{1}[t-2], \\
& y[0]=y[-1]=y[-2]=y[-3]=0
\end{aligned}
$$

The meaning of the functional corresponded to: $I=0.105101$, which was two-fold less than for a model with one input. An optimal structure of the model obtained (12) was further used to solve our goal - to estimate influence of fuel feed pedal pressing rate on exhaust gases opacity quantitatively. 


\section{Practical application}

An algorithm of estimating car exhaust gases opacity using static models. The point of calculation using static models is as follows.

1. At least two measures of diesel engine exhaust gases opacity are performed in free acceleration mode: the first - quick acceleration, the second - slower acceleration.

2. Opacity is estimated in a set mode at a maximum crank shaft rate.

3. The value of coefficient $b$ is defined, characterizing intensity of change of a parameter characterizing fuel feed pedal pressing rate, by the formula (3).

4. Exhaust gases opacity is brought (adjusted) to $t_{\mathrm{p}}-$ a regulated value of time, $\mathrm{s}$, change of a parameter, characterizing fuel feed pedal pressing rate, by the formula (4).

Let us illustrate this method of exhaust gases opacity measurement using a particular numerical example. In a course of 4 measurements of exhaust gases opacity in free acceleration mode we obtained the following opacity values $D_{i}$ and corresponding to them values of pedal pressing time $t_{i}: D_{1}=94.53 \% ; t_{1}=0.29 \mathrm{~s} ; D_{2}=49.62 \% ; t_{2}=3.13 \mathrm{~s} ; D_{3}=97.87$ $\% ; t_{3}=0.12 \mathrm{~s} ; D_{4}=51.15 \% ; t_{4}=2.84 \mathrm{~s} ; D_{0}=10 \%$.

If we insert in formulas (3), (4) values of the first two measurements, we will obtain

$\left.b=\ln \left[D_{2}-D_{0}\right) /\left(D_{1}-D_{0}\right)\right] /\left(t_{2}-t_{1}\right)=\ln [(49.62-10) /(94.53-10)] /(3.13-0.29)=-0.25 ;$

$D_{\text {corrected }}=D_{0}+\left(D_{1}-D_{0}\right) / e^{b \cdot\left(t_{\text {regulated }}-t_{1}\right)}=10+(94.53-10) \cdot e^{-0.25 \cdot(1-0.29)}=79.94 \%$.

If we insert in formulas (3), (4) values of the third and fourth measurements, we will get

$\left.b=\ln \left[D_{3}-D_{0}\right) /\left(D_{4}-D_{0}\right)\right] /\left(t_{3}-t_{4}\right)=\ln [(97.87-10) /(51.15-10)] /(0.12-2.84)=-0.26 ;$

$D_{\text {corrected }}=D_{0}+\left(D_{3}-D_{0}\right) / e^{b \cdot\left(t_{\text {regulated }}-t_{3}\right)}=10+(97.87-10) \cdot \mathrm{e}^{-0.26 \cdot(1-0.12)}=78.74 \%$.

We can see that using the method being proposed at any accelerator pedal pressing rate, adjusted (brought to $1 \mathrm{~s}$ of pedal pressing time) values of smoking are very close to each other, which means that a task of reduction the spread in measurement results by taking into account a factor conditioning these spreads is solved.

An algorithm of estimating car exhaust gases opacity using dynamic models. An algorithm of estimating car exhaust gases opacity using dynamic models includes three stages:

1. Exhaust gases opacity of a particular car is measured (fuel feed pedal is quickly pressed-pressing time is no more than $0.5 \mathrm{~s}$ ), whereby a full image of exhaust formation in time is registered, as well as change of control factors - position of the fuel feed pedal and crank shaft rate ( see parameters: $u, u_{l}, \mathrm{y}^{*}$, fig. 4).

2. Coefficients of exhaust gases opacity are defined for dynamic model of this car (the principle of adjustment of equation parameters (12) is shown in Table 2).

\begin{tabular}{|c|c|c|c|c|c|c|c|c|c|}
\hline \multirow{2}{*}{$\begin{array}{c}\text { Iteration } l \\
\text { steps }\end{array}$} & \multicolumn{8}{|c|}{ Coefficients of a dynamic model } & \multirow{2}{*}{$\begin{array}{c}\text { Functional } \\
I\end{array}$} \\
\hline & $\alpha_{1}$ & $\alpha_{2}$ & $\alpha_{3}$ & $\alpha_{4}$ & $\alpha_{5}$ & $\alpha_{6}$ & $\alpha_{7}$ & $\alpha_{8}$ & \\
\hline 0 & 0.78359 & -0.09276 & 0.04793 & 0.01702 & -0.12619 & 0.28676 & 4.55552 & -4.61362 & 0.29343 \\
\hline 1 & 0.24668 & 0.23700 & 0.02432 & 0.08734 & -0.0235 & 0.33075 & 7.30231 & -7.4238 & 0.13200 \\
\hline 2 & 0.52672 & -0.1210 & 0.12406 & 0.06584 & 0.09819 & 0.22609 & 7.01706 & -7.1428 & 0.09822 \\
\hline 3 & 0.52050 & -0.0334 & 0.03087 & 0.09099 & 0.13970 & 0.15257 & 6.88082 & -6.9914 & 0.09795 \\
\hline 4 & 0.54283 & -0.0957 & 0.08939 & 0.07162 & 0.12134 & 0.17268 & 6.89233 & -7.0034 & 0.09778 \\
\hline 5 & 0.53643 & -0.0844 & 0.07878 & 0.07632 & 0.11942 & 0.17601 & 6.91110 & -7.0230 & 0.09777 \\
\hline
\end{tabular}

Table 2. Results of step-by-step calculations

After the adjustment the model will be as follows: 


$$
\begin{aligned}
& y[t]=0,536437 \cdot y[t-1]-0,0844866 \cdot y[t-2]+0,0787829 \cdot y[t-3]+ \\
& +0,0763274 \cdot y[t-4]+0,1194237 \cdot u[t-1]+0,1760184 \cdot u[t-2]+ \\
& +6,9111057 \cdot u_{1}[t-1]-7,0230087 \cdot u_{1}[t-2], \\
& y[0]=y[-1]=y[-2]=y[-3]=0 .
\end{aligned}
$$

Its graphical analogue is presented in fig. 4.

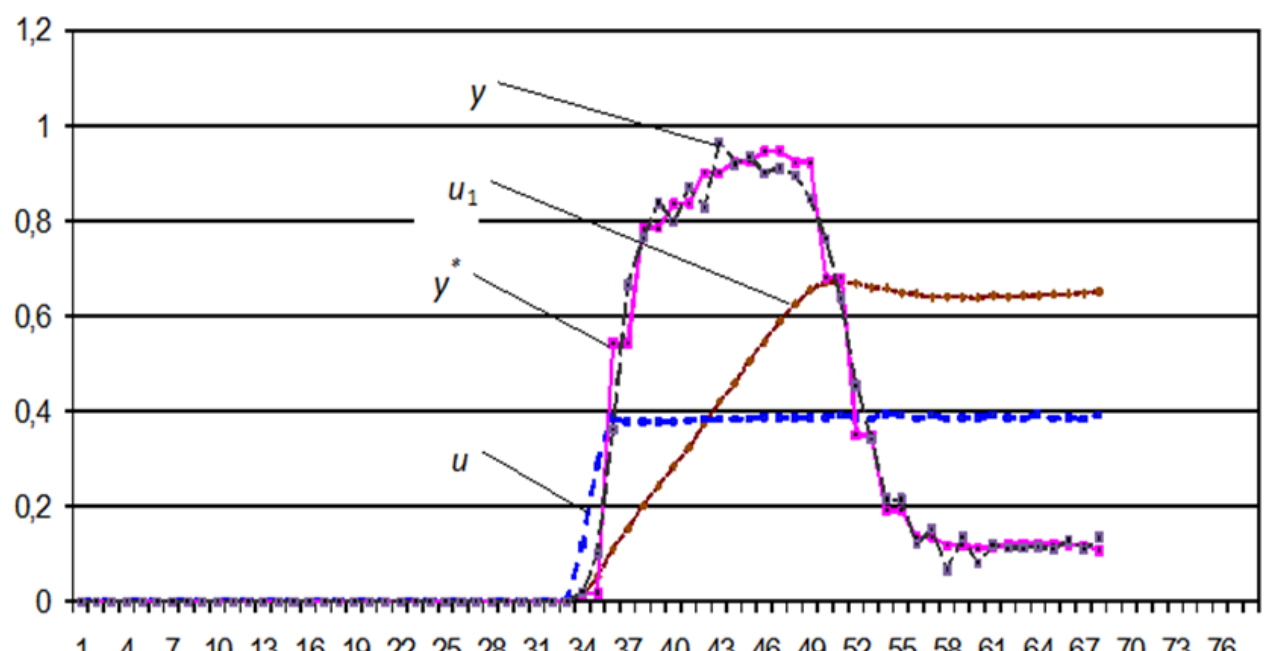

Fig. 4. The graphical analogue of obtained model due to opacity forming

3. A standard control signal is sent in the model input, and exhaust gases opacity is calculated according to the dynamic model obtained upon the condition of the standard control signal (factor). Exhaust gases opacity obtained in time will be the characteristic of this car (fig. 5).
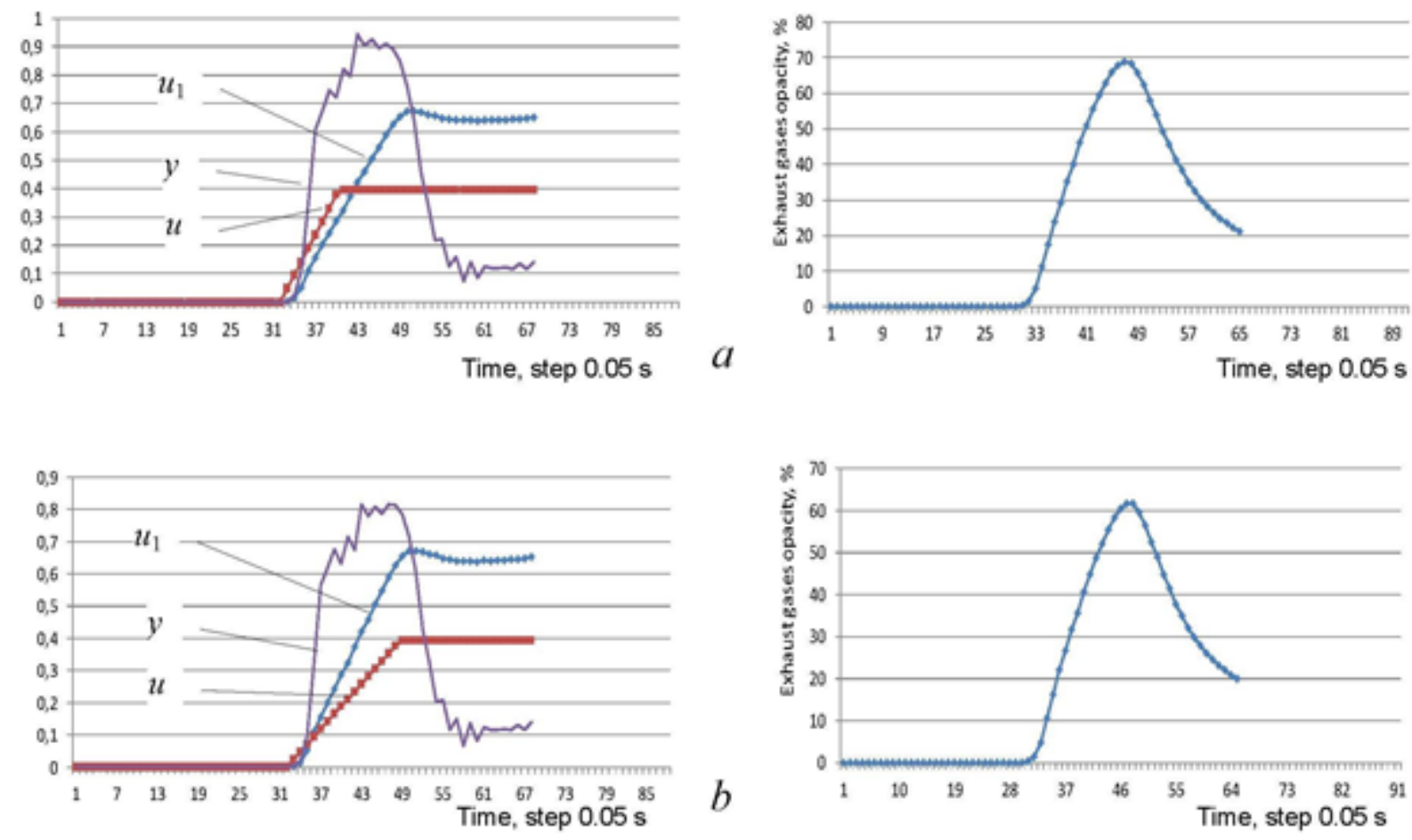

Fig. 5. Graphical representation of results of KamAZ-740 diesel engine exhaust gases opacity modeling: $a$ - pedal pressing time is $0.05 \mathrm{~s} ; b$ - pedal pressing time is $1.0 \mathrm{~s}$. 
These examples show that calculation algorithms of opacity of exhaust gases of diesels using static and dynamic models make it possible to identify difference in fuel feed pedal pressing rate during testing and exclude probability of receiving inaccurate measurement results.

\section{Conclusion}

The obtained results demonstrated the direct impact of fuel feed pedal pressing rate in free acceleration mode on opacity of exhaust gases. Therefore, article 2.5 of the Appendix of 5 Rules of UNECE No. 24, that provide a vague regulation of opacity estimates of the exhaust gases require revision and design clear requirement relating quantitative index concerning for fuel feed pedal pressing rate index in free acceleration mode.

Techniques of correcting opacity estimates of the diesel exhaust gases were developed based on static and dynamic models. For opacity estimation of the exhaust gases the techniques suggest to register either the signal for the time of fuel feed pedal pressing rate in free acceleration mode from minimal to maximal level or the signal of reaching its rotation peak by the crank-shaft

The application of findings of the study and techniques will allow elimination of mistakes during engines trend monitoring and maintenance for further release to service of vehicle and cut down test expenses.

\section{References}

[1] Dragomir, G.; Beles, H.; Blaga, V.; Stanasel, I.; Negrea, V.D. \& Blaga, F.S. (2008). Diesel Engines Pollution and Functional-Constructive Performances Compromise Optimization, using Fuzzy Sets, Annals of DAAAM for 2008 \& Proceedings of the 19th International DAAAM Symposium, 22-25th October 2008, Trnava, Slovakia, ISSN 17269679, ISBN 978-3-901509-68-1, Katalinic, B. (Ed.), pp. 0413-0414, Published by DAAAM International Vienna, Vienna.

[2] Ostoia, D.; Negoitescu, A. \& Tokar, A. (2008). The Wearing Out Compensation of Diesel Engines Combustion Chambers by Modern Systems Implementation, Annals of DAAAM for 2008 \& Proceedings of the 19th International DAAAM Symposium, 22-25th October 2008, Trnava, Slovakia, ISSN 1726-9679, ISBN 978-3901509-68-1, Katalinic, B. (Ed.), pp. 0947-0948, Published by DAAAM International Vienna, Vienna.

[3] Sabau, A.; Barhalescu, M.; Oanta, E. \& Dumitrache, C. (2009). Simplified Model for Combustion Reactions in Diesel Engine, Annals of DAAAM for 2009 \& Proceedings of the 20th International DAAAM Symposium, 25-28th November 2009, Vienna, Austria, ISSN 1726-9679, ISBN 978-3-901509-70-4, Katalinic, B. (Ed.), pp. 0811-0812, Published by DAAAM International Vienna, Vienna.

[4] Jamradloedluk, J. (2009). Preparation and Characterization of Methyl Ester from High Free Fatty Acid Oil by Two STEP Chemical Process, Annals of DAAAM for 2009 \& Proceedings of the 20th International DAAAM Symposium, 25-28th November 2009, Vienna, Austria, ISSN 1726-9679, ISBN 978-3-901509-70-4, Katalinic, B. (Ed.), pp. 0939-0940, Published by DAAAM International Vienna, Vienna.

[5] Irimescu, A.; Ionel, I.; Dungan, L. I. \& Cioabla, A. E. (2010). Initial Theoretical Study for a Heavy Duty Diesel Engine Conversion to Biogas Fuelling, Annals of DAAAM for 2010 \& Proceedings of the 21 st International DAAAM Symposium, 20-23rd October 2010, Zadar, Croatia, ISSN 1726-9679, ISBN 978-3-901509-73-5, Katalinic, B. (Ed.), pp. 0999-1000, Published by DAAAM International Vienna, Vienna.

[6] Sauciuc, A.; Dumitrescu, L. \& Manciulea, I. (2010). Purification Steps for Biodiesel Synthesized from Waste Oils, Annals of DAAAM for 2010 \& Proceedings of the 21st International DAAAM Symposium, 20-23rd October 2010, Zadar, Croatia, ISSN 1726-9679, ISBN 978-3-901509-73-5, Katalinic, B. (Ed.), pp. 1309-1310, Published by DAAAM International Vienna, Vienna.

[7] Plsek, S. (2011). Controling and Monitoring System for the Production of Biodiesel, Annals of DAAAM for 2011 \& Proceedings of the 22nd International DAAAM Symposium, 23-26th November 2011, Vienna, Austria, Volume 22, No. 1, ISSN 1726-9679, ISBN 978-3-901509-83-4, Katalinic, B. (Ed.), pp. 1549-1550, Published by DAAAM International Vienna, Vienna.

[8] Aguilera, V.; Tordeux, A. (2014) A new kind of fundamental diagram with an application to road traffic emission modeling / Journal of Advanced Transportation. 2014; 48: 165-184.

[9] UNECE Rules No. 24 Uniform provisions concerning: I. The approval of compression ignition (C.I.) engines with regard to the emission of visible pollutants; II. The approval of motor vehicles with regard to the installation of C.I. engines of an approved type; III. The approval of motor vehicles equipped with C.I. engines with regard to the emission of visible pollutants by the engine; IV. The measurement of power of engines - access mode: http://www.unece.org/fileadmin/DAM/trans/main/wp29/wp29regs/r024r2e.pdf.

[10] Blyankinshtein I.M. On the nature of instability of diesel engine exhaust smoking measurement results / I.M. Blyankinshtein, E.S. Voevodin, K.V. Danilov//Transport means of Siberia: an interuniversity composite scientific treaties with international participation. Ed. 8 / Edited by S.P. Eresko. - Krasnoyarsk: IPC KSPU, 2002. - Pp. 240248.

[11] OEM technological instruments/Exhaust Emission Testing/Driving Robot \& Automation Systems. - access mode: http://www.oemtesting.com/exhaust-mission-testing.php.

[12] ABDynamics/ Driving Robot/ Pedal Robots and Actuators. - access mode: http://www.abd.uk.com/en/driving_robots/pedal_robots 
[13] Pat. 2215276 RF, MPK7 G 01 M 15/00. Means of diesel engine exhaust smoking measurement (variants) / I.M. Blyankinshtein, E.S. Voevodin; an applicant and patentee is Krasnoyarsk State Polytechnic University. - No. [2]. 2002131431/06; appl. 22.11.2002; publ. 27.10.2003, Bull. No. 30. - 9 p.: ill.

[14] Blyankinshtein I.M. Method of diesel engine exhaust smoking measurement / I.M. Blyankinshtein, E.S. Voevodin // Organization and safety of road traffic in big cities: composite report of the sixth international conference. - St.P.: St.-Petersburg State University of Architecture and Civil Engineering, 2004. - Pp. 347 - 349.

[15] Ruban A.I. Identification of nonlinear dynamic objects based on the algorithm of the sensitivity / A.I. Ruban. Tomsk: Publishing house of Tomsk. State University, 1975.

[16] Blyankinshtein I.M. Identification of dynamic characteristics of diesel engine exhaust smoking in free acceleration regime / I.M. Blyankinshtein, E.S. Voevodin, A.I. Ruban // Krasnoyarsk State Polytechnic University's Gazette. Ed. 34. Transport. - Krasnoyarsk: IPC KSPU, 2004. - pp. 149-155. 